\title{
A Review on Modes of Transmission of COVID-19
}

\author{
Rupali Masand $^{1 *}$, Abhilash Jadhao ${ }^{1}$ and Sameer Jadhav ${ }^{2}$ \\ ${ }^{1}$ Department of Veterinary Pathology, GADVASU, Ludhiana, Punjab, India \\ ${ }^{2}$ Department of Veterinary Biochemistry, KNP College of Veterinary Science, \\ Shirwal, Satara, Maharashtra., India \\ *Corresponding author
}

\section{A B S T R A C T}

The World Health Organization declared Covid-19 as a pandemic on March 11, 2020. It is of prime interest of a public health concern and global emergency to control its transmission. Covid-19 is caused by severe acute respiratory distress syndromecoronavirus-2 (SARS-CoV-2) which is highly infectious agent from Corona virus family

\section{Keywords}

Covid-19, SARSCoV-2, Pandemic and Pneumonia

\section{Article Info}

Accepted:

10 January 2021

Available Online: 10 February 2021 which is having many pathogenic forms like MERS-CoV \& SARS-CoV experienced during past outbreaks. The disease may be transmitted by either by COVID-19-positive individuals or from a contaminated environment. SARS-CoV-2 is thought to commonly spread through respiratory droplets mainly by coughing and sneezing of an infected patient and there is a strong possibility of community transmission. Primarily, there are two methods of transmission of COVID-19 specifically direct and indirect. The direct mode includes transmission via aerosols or in the form of respiratory droplet nuclei; other body fluids and secretions (for example, feces, saliva, urine, semen, and tears) and via from mother to child. Indirect transmission may occur through fomites or surfaces present within the immediate environment of an infected patient and objects used on the infected person. Transmission dynamics of COVID-19 are heterogeneous with a major role for super spreading events in sustaining the epidemic. Based on the reported literature, studies revealed that COVID-19 is primarily transmitted human-to-human via oral and respiratory aerosols and droplets with the virus-contaminated environment play a lesser role in the propagation of disease. Besides this there are several modes of transmission reported. This review paper elaborates briefly about different modes of transmission of COVID-19 virus in the community and proposes measures to diminish the danger of spread within population.

\section{Introduction}

Coronaviruses generally cause gastrointestinal and respiratory tract infections and are inherently categorized into four major types namely Gamma coronavirus, Delta coronavirus, Beta coronavirus and Alpha coronavirus (Ge XY et al., 2017).Corona virus infections were thought to infect only animals means occur animal to human infection only until a severe acute respiratory syndrome (SARS) outbreak caused by SARSCoV, 2002 occurred in Guangdong, China. SARS-CoV causes acute lung injury and 
acute respiratory distress syndrome (ARDS) which leads to pulmonary failure and result in fatality.

At the end of 2019, a novel coronavirus was identified as the cause of a cluster of pneumonia cases in Wuhan, a city in the Hubei Province of China and spread rapidly which resulted in an epidemic throughout China followed by a global pandemic. However, this virus causes rapid human to human transmission through aerosols, droplets and direct contact. In February 2020, the World Health Organization (WHO) named the disease COVID-19, which stands for coronavirus disease -2019 .

Covid-19 virus is a pathogenic virus and cause of current outbreak of pneumonia (Hui et al., 2020). It belongs to the $\beta$-coronavirus family in the same subgenus as the severe acute respiratory syndrome (SARS) virus. International Committee on Taxonomy of Viruses (ICTV) has proposed that Covid-19 virus be designated severe acute respiratory syndrome coronavirus 2 (SARS-CoV-2) (Gorbalenya et al., 2020). Bats occur to be the COVID-19 virus reservoir, but the intermediate host(s) has not been detected till now.

COVID-19 virus is transmitted directly from bats or through some other mechanism which is unknown (Perlman, 2020).However, sequence-based analysis suggested bats as the key reservoir but zoonotic source of SARS$\mathrm{CoV}-2$ is not yet confirmed.

Similar to other viruses, SARS-CoV-2 has many potential natural hosts, intermediate hosts and final hosts. SARS-CoV-2 has high transmissibility and infectivity but a low mortality rate (Bell, 2006) as compared with severe acute respiratory syndrome and Middle East respiratory syndrome coronaviruses respectively.

\section{Transmission}

In this paper we have reviewed the extensive accumulating evidence about the transmission of Covid-19, evidence for various modes of transmission. SARS-CoV-2 is spread primarily via respiratory droplets during close contact. Infection can be spread by asymptomatic, presymptomatic and symptomatic carriers. Wiersinga et al., (2020) stated that the average time from exposure to symptoms onset is 5 days and $97.5 \%$ of people who develop symptoms do so within 11.5 days. One of the reasons for cross species transmission and rapid infection could be the involvement of spike glycoprotein which assorted SARS-CoV (CoVZXC21 or CoVZC45) with the RBD of another Beta $\mathrm{CoV}$.

Respiratory transmission is the dominant mode of transmission in corona virus infection. Vertical transmission occurs very rarely and transplacental transmission has been documented. Cats and ferrets can be infected and transmit to each other, but there are no reported cases to date of transmission to humans; minks transmit to each other and to humans. Direct contact and fomites transmission are presumed but are likely only an unusual mode of transmission. Although live virus has been isolated from saliva \& stool and viral RNA has been isolated from semen and blood donations (Meyerowitz et al., 2020). Contact transmission (contact with nasal, oral and eye mucous membrane) and direct transmission (sneeze, cough and droplet inhalation transmission) are found to be the common mode for the transmission of novel COVID-19.

\section{Respiratory transmission}

COVID-19 can be transmitted either directly through sneeze, cough or inhalation of droplets from infected human or also through 
contact with nasal mucous membranes and fomites. Previous studies have shown that besides sneezing \& coughing, normal breathing and speech can also generate aerosol ranging from 0.75 to $1.1 \mu \mathrm{m}$, which is smaller than the aerosol generated by sneezing or coughing $(\sim 5 \mu \mathrm{m})$ and hence it can transmit virus up to greater range (Asadi et al., 2019). It is reported that the amount of aerosol generated through more than 4 minutes of speaking and breathing is equivalent to the concentration of aerosol emitted from coughing for 30 seconds (Chao et al., 2009; Johnson et al., 2011). Recent case studies reported also showed that transmission of aerosol emitted through these routes over a short distance in family clusters among several Chinese cities (Chan et al., 2020; Yu et al., 2020), restaurant in Guangzhou, China (Jianyun et al., 2020) and choir group in Mount Vernon, WA, USA (Read et al., 2020). Human activity can resuspend the aerosols and droplets deposited on surfaces and floors and hence comprises the majority of the aerosols within an occupied setting (Hospodsky et al., 2015; Kwan et al., 2020). Recent studies reported the detection of airborne levels of RNA SARS-CoV-2 virus in indoor air samples of COVID-19 patient room (Chia et al., 2020; Liu et al., 2020a; Santarpia et al., 2020), hallway spaces outside patients' rooms (Santarpia et al., 2020) and medical staff areas (Liu et al., 2020a) by using quantitative RT-PCR.

Chia and his coworkers (2020) reported that the size of aerosol present in medical staff were smaller $(0.25$ to $2.5 \mu \mathrm{m}$ and $>2.5 \mu \mathrm{m})$ than those found in patient rooms ( 1 to $4 \mu \mathrm{m}$ and $>4 \mu \mathrm{m}$ ) and it is observed that larger aerosols $(>4 \mu \mathrm{m})$ deposited in the upper and central airways (nasopharynx and tracheobronchial) and are expelled out through mucociliary clearance whereas smaller aerosols $(<4 \mu \mathrm{m})$ deposited in the deep lung (alveoli) with epithelial cells rich in angiotensin-converting enzyme 2 (cellular entry receptor of SARS-CoV-2) and hence facilitates its transmission efficiency (Hamming et al., 2004). ACE-2 plays an important role in human-to-human and crossspecies transmission (Tortorici and Veesler, 2019) by binding with virion Spike (S) glycoprotein present on the surface of the SARS-CoV-2 virus which facilitates its entry into the host cell where genome RNA of the virus is released and uncoated into cytoplasm and translated into two polyproteins, ppla and pplab (de Wilde et al., 2018) forming replication-transcription complex (RTC) in double-membrane vesicle (Sawicki and Sawicki, 2005) and continues to replicate and synthesize a nested set of subgenomic RNAs (Hussian et al., 2008) along with endoplasmic reticulum and Golgi (Perrier et al., 2019), newly formed genomic RNA, envelope glycoproteins assemble and nucleocapsid proteins leading to formation of viral particle buds which fuses with the plasma membrane to release the virus (Guo et al., 2020).

\section{Contact transmission}

Human-to-human transmission of COVID-19 virus is mainly reported between family members, relatives and friends who contacted with infected patients or incubation carriers (Guo et al., 2020). Contact transmission occurs through indirect contact with the surface of contaminated objects including contaminated public transport handrails, door, handles, seats, elevator surfaces etc. or indirectly infected through contact with mucous membranes (nasal, oral, conjunctiva, etc.). It is reported that the nucleic acid of 2019-nCoV has been detected in the door handles of hospitals in Shandong and Guangzhou (New Group of Experts on the prevention and control of Chinese Preventive Medicine Association coronavirus pneumonia, 2020; Yang et al., 2020). 


\section{Faeco-oral transmission}

Studies have shown that besides respiratory droplets, fecal-oral route is also a potent mode for transmission of COVID-19 infection ( $\mathrm{Gu}$ et al., 2020; Tian et al., 2020). Fecal oral transmission occurs through direct or indirect contact with pathogens from contaminated fecal excreta (Graaf et al., 2017). Holshue et al., (2020) reported first case of fecal-oral transmission by detecting the RNA of SARSCoV-2 in the stool specimen of the COVD-19 infected patient in United States. It has been reported that ACE2 are on abundantly expressed in esophageal, gastric, duodenal and rectal epithelial cells and absorptive enterocytes of ileum and colon making gastrointestinal tract susceptible to SAR-SCoV-2 infection and hence suggestive of possible faecal transmission (Du et al., 2020; Zhang et al., 2020a; Xiao et al., 2020). ACE2 of host cell binds with S1 domain spikeprotein of SARS-CoV-2 virus facilitating the viral entry (Batlle et al., 2020; Liu et al., 2020b; Walls et al., 2020; Wrapp et al., 2020) and synthesis of virus-specific RNA and protein in the cytoplasm leading to new virions formation (Weiss et al., 2020) and are released into gastrointestinal tract. Recent study showed isolation of SARS-CoV-2 virus from the stool and confirmed the shedding of infectious virions to the gastrointestinal tract (Xiao et al., 2020).

Various studies reported viral shedding from feaces for long duration even after negative conversion in throat and pharyngeal swabs, suggestive of fecal-oral transmission may serve as an alternative infection route for SARS-CoV-2 (Chen et al., 2020; Yang et al., 2020) and occur even after viral clearance in respiratory tract. Zhang and his coworkers (2020b) reported high accuracy of COVID-19 nucleic acid in stool samples and presence of viral nucleic acid in stool are not correlated with severity of pneumonia or GI manifestation.

\section{Food-borne transmission}

Studies revealed that most of the initial cases originated from Huanan South Seafood Market in Wuhan where along with seafood, live and slaughtered chicken, bats, deer, snakes. pheasants, marmots, organs of rabbits and other exotic animals are sold (National Health Commission of the People's Republic of China, 2020; World Health Organization, 2020). Studies demonstrated that the genome sequence of SARS-CoV-2 virus is $96.2 \%$ identical to a bat CoV RaTG13 and hence, bat has been suspected as natural host for the origin of virus and SARSCoV-2 may transmitted from bats via unknown intermediate hosts to infect humans (Zhou et al., 2020). Liu et al., (2020c) found similar spike protein and host ACE2 receptors through protein sequences alignment and phylogenetic analysis in many species such as turtles, pangolin and snacks indicating more possibility of alternative intermediate hosts.

\section{Water-borne transmission}

SARS-CoV-2 infected patients may shedding of the virus in their stool and hence, wastewaterbased epidemiology can quantify the prevalence of infection in wastewater among the population. Wastewater-based epidemiology is a useful approach to check the prevalence of virus in specific wastewater treatment plant catchment population as viruses are excreted from both asymptomatic and symptomatic individuals in the untreated wastewater in a catchment (Sinclair et al., 2008; Ahmed et al., 2020; Xagoraraki and O'Brien, 2020) and hence, used as early warning for outbreaks disease, resurgence (Kissler et al., 2020), status and trends, suppression, subsidence of Covid-19 and give information regarding the efficacy of public health interventions, as demonstrated previously for enteric viruses including poliovirus, norovirus and hepatitis A virus (Asghar et al., 2014; Hellmer et al., 2014). 
Ahmed et al., (2020) confirmed SARS-CoV-2 virus from wastewater in a catchment in Australia using reverse transcriptase quantitative polymerase chain reaction. Recent studies also reported molecular detection of SARS-CoV-2 virus in in wastewater samples in other parts of the world such as Netherlands and USA (Lodder and Husman, 2020; Medema et al., 2020; Wu et al., 2020b; 2020c;Bar Or et al., 2020; La Rosa et al., 2020; Nemudryiet al., 2020; Randazzo et al., 2020; Wurtzeret al., 2020). Hart and Halden (2020) detected SARS-CoV2 virus from wastewater computationally and also found temperature and in-sewer travel time severely impact virus detectability.

\section{Ocular transmission}

Transmission of COVID-19 infection through ocular secretion is currently unknown, however theories included migration from the nasopharynx via nasolacrimal duct or hematogenous spread through lacrimal gland or direct inoculation of ocular tissue with pathogen-loaded droplets can be the possibilities for ocular transmission of COVID-19 (Bostanci and Ozates, 2020; Loon et al., 2020; Seah and Agrawal, 2020; Hu et al., 2020). Various studies shown that cellular receptors for SARS-COV-2 virus is ACE2 present abundantly in the respiratory tract (Hamming et al., 2004) and digestive tract (Du et al., 2020; Zhang et al., 2020a; Xiao et al., 2020) and also in other organs of the body (skin, lymph nodes, thymus, bone marrow, spleen, liver, and brain) (Hamming et al., 2004), but confirmation of ACE-2 in conjunctival epithelium still to be confirmed.

Chinese expert got infected with COVID-19 and reported first case conjunctivitis suggesting route of conjunctival infection and tear transmission (Lu et al., 2020). Wu et al., (2020a) reported 12 patients with ocular symptoms and two positive conjunctival swabs from 38 COVID-19-positive patients in Hubei Province, China. Another study reported detection of SARS-CoV-2 in tears of COVID-19 infected patients by using quantitative reverse transcription polymerase chain reaction (RT-PCR) (Karimi et al., 2020). National Institute for Infectious Diseases in Rome, Italy also reported ocular symptoms and confirmed SARS-CoV-2positive RT-PCR conjunctival samples in a COVID-19 infected patient (Colavita et al., 2020). Recent studies suggest that tears act as potential source for this infection and conjunctiva may sustain viral replication for an extended period of time.

\section{Vertical transmission}

Kotlyar et al., (2021) stated that vertical transmission of SARS-CoV-2 in the third trimester of pregnancy is approximately $3.2 \%$ (22/936) by infant nasopharyngeal swab testing, with SARS-CoV-2 RNA positivity in other test sites ranging from $0 \%(0 / 51)$ in amniotic fluid and urine $0 \%(0 / 17), 3.6 \%$ $(1 / 28)$ in the cord blood, $7.7 \%(2 / 26)$ by placental sample analysis, $9.7 \%(3 / 31)$ by rectal or anal swab, and $3.7 \%(3 / 81)$ by serology. Another case has documented evidence of a neonate tested positive for the SARS-CoV-2 infection after $30 \mathrm{hr}$. of his birth from a COVID-19 affected mother. The samples in this study were not directly collected from the amniotic fluid inside the uterus but were collected from the throat of the newborn after birth, so the evidence of vertical transmission is still obscure form this clinical case (Zhang et al., 2020c).

There is no obvious proof of any intrauterine or vertical transmission form infected mother to newborn is addressed and infected pregnant women are found to show similar clinical manifestations when compared to affected non-pregnant females(Chen et al., 2020b; Li et al., 2020). The basic concern in regards to 
the vertical transmission has shown up from the severe manifestations confirmed in previous literature where the pregnant women were found to show more severe outcome during SARS and MERS epidemics as compared with the general population(Favre et al., 2020; Schwartz and Graham, 2020).Another study has reported that there is no evidence of in-utero or vertical transmission of SARS-CoV-2 virus involved 38 pregnancies and also showed similar results with previous studies on MERS-CoV and SARS- CoV epidemics. No significant and scientific establishment of in-utero or vertical transmission of SARS-CoV-2 virus has been recorded in different investigations by several countries including China (Liang and Acharya, 2020; Chen et al., 2020a, 2020b; Qiao et al., 2020; Favre et al., 2020), Iran (Mardani et al., 2020) and USA (Rasmussen et al., 2020). None of the research has warranted the transmission of SARS-CoV-2 infection through breast milk but the droplets released during breast feeding could contribute for the transmission of infection from mother to the newborn (Rasmussen et al., 2020).

One of the examinations in Iran has proven the death of two affected pregnant women with SARS-COV-2 infection after the delivery (out of 3 ) because of ARDS. However, the infants after birth were tested negative for COVID-19 disease (Tasnim Agency, 2020).In 20 January to 31 January, 2020 at Zhongnan Hospital of Wuhan University, China conducted study on affected 9 women in third trimester of pregnancy with no any chronic disease conditions (hypertension, diabetes, cardiovascular disease etc.) has addressed no proof of intra-uterine transmission after screening of the samples collected from the amniotic fluid, blood from the blood cord, breast milk and throat swabs from the neonate with RT-PCR (Chen et al., 2020b).
Hong Kong, a city in China had experienced outbreak of SARS where, $30 \%$ morality (3 died out of 10) among pregnant women has been identified, but there is no fatality among 30 affected non-pregnant women was recorded (Creanga et al., 2020). Zeng et al., (2020) gave evidence that COVID-19 infected neonates may got infected from their infected mothers through in utero transmission based upon elevated antibody level (IgM and $\mathrm{IgG}$ ) and abnormal cytokines levels of blood drawn from the neonates. So, further investigation and new research related to vertical transmission of corona infection is necessary due to small size data available (Dong et al., 2020; Kimberlin and Stagno, 2020).

In conclusions the novel Covid-19 virus now spread rapidly around world and primarily originated from seafood market at Wuhan city (China). Based on literature and reported data the pneumonia outbreak caused by SARSCoV-2 is mainly transmitted by respiratory route but other modes of transmission discussed are also potential source of spread of virus in the community. Long duration of pandemic has brought disruption to the lives of people and their willingness to adhere to strict rules and lockdowns might wane. As cases of COVID-19 increase globally, we need to more fully understand the transmission routes. It is crucial that we embrace new research and do not rely on recommendations based on old data so that clearer and more effective infection control guidance can be provided in the face of pandemic fatigue.

Meyerowitz (2020) stated that we must continue to stay up to date with the new and emerging evidence and work quickly to revise our policies to reflect this new information. Even though knowledge about Covid-19 virus is still rapidly evolving and a more studies are required to assess other potential modes of transmission. 


\section{Acknowledgment}

Special thanks to Dr. Sameer Jadhav (Assistant Professor \& Head, Dept. of Veterinary Biochemistry, KNP College of Veterinary Science, Shirwal (Maharashtra) for their valuable guidance.

\section{References}

Ahmed, W., Angel, N., Edson, J., Bibby, K., Bivins, A. and O'Brien, J.W. 2020. First confirmed detection of SARS-CoV-2 in untreated wastewater in Australia: a proof of concept for the wastewater surveillance of COVID-19 in the community.Sci.Total Environ. 728:138764.

Asadi S., Anthony S. W., Christopher D. Cappa, Santiago Barreda, Nicole M. Bouvier and Ristenpart W.D. 2019. Aerosol emission and super emission during human speech increase with voice loudness. Scientific Reports.9:2348.

Asghar H, Diop OM, Weldegebriel G, Malik F, Shetty, S., Bassioni, L. El, Akande, A.O., Maamoun, E. Al, Zaidi, S., Adeniji, A.J., Burns CC., Deshpande, J., Oberste, M.S. and Lowther, S.A. 2014. Environmental surveillance for polioviruses in the global polio eradication initiative. J. Infect. Dis. 210: S294-S303.

Bar Or, I., Yaniv, K., Shagan, M., Ozer, E., Erster, O. and Mendelson, E. 2020. Regressing SARS-CoV-2 sewage measurements onto COVID-19 burden in the population: a proof-of-concept for quantitative environmental surveillance. MedRxiv. doi: 10.1101/2020.05.25.20112706. 2020.05.25.20112706.

Batlle D, Wysocki J and Satchell K. 2020. Soluble angiotensin-converting enzyme 2: a potential approach for coronavirus infection therapy. Clin. Sci.
134(5):543-545.

Bostanci Ceran B. and Ozates S.2020. Ocular manifestations of coronavirus disease. Graefes Arch Clin Exp Ophthalmol. $6: 1-5$

Chan JF-W. 2020. A familial cluster of pneumonia associated with the 2019 novel coronavirus indicating person-toperson transmission: a study of a family cluster. The Lancet. 395: 514-23.

Chao CYH. M.P. Wan, B L. Morawska, C.G.R. Johnson, C.Z.D. Ristovski, C.M. Hargreaves, K. Mengersen, S. Corbett, Y. Li, fX. Xie, and D. Katoshevskig. 2009. Characterization of expiration air jets and droplet size distributions immediately at the mouth opening. J Aerosol Sci. 40: 122-33.

Chen G, Wu D, Guo W, Cao Y, Huang D, Wang $\mathrm{H}$, Wang $\mathrm{T}$, Zhang $\mathrm{X}$, Chen $\mathrm{H}$, Yu H, Zhang X, Zhang M, Wu S, Song J, Chen T, Han M, Li S, Luo X, Zhao J and Ning Q. 2020a. Clinical and immunologic features in severe and moderate coronavirus disease 2019. J Clin Invest. 130(5): 2620-2629.

Chen H, Guo J, Wang C, Luo F, Yu X, Zhang W, Li J, Zhao D, Xu D, Gong Q, Liao J, Yang H, Hou W and Zhang Y. 2020b. Clinical characteristics and intrauterine vertical transmission potential of COVID-19 infection in nine pregnant women: a retrospective review of medical records. Lancet. 7, 395(10226): 809-815.

Chen Y, Chen L. and Deng Q. 2020. The presence of SARS-CoV-2 RNA in the feces of COVID-19 patients. J Med Virol. 92: 833-840.

Chen YH, Keller J, Wang IT, Lin CC and Lin HC. 2012. Pneumonia and pregnancy outcomes: a nationwide populationbased study. Am J Obstet Gynecol. 207(4): 288.e1-7.

Colavita F, Lapa D., Carletti F. et al., 2020. SARS-CoV-2 isolation from ocular 
secretions of a patient with COVID-19 in Italy with prolonged viral RNA detection. Ann Intern Med. 20-1176.

Creanga AA, Johnson TF, Graitcer SB, Hartman LK, Al-Samarrai T, Schwarz AG, Chu SY, Sackoff JE, Jamieson DJ, Fine AD, Shapiro-Mendoza CK, Jones LE, Uyeki TM, Balter S, Bish CL, FinelliL, Honein MA. Severity of 2009 pandemic influenza A (H1N1) virus infection in pregnant women. Obstet Gynecol 2010; 115(4):717-726.

De Wilde A.H., Snijder E.J., Kikkert M. and Van Hemert M. J. 2018. Host factors in coronavirus replication. Curr. Top Microbiol Immunol. 419:1-42.

Dockery DM, Rowe SG, Murphy M.A. and Krzystolik M. G.2020. The ocular manifestations and transmission of covid-19:Recommendations for prevention.The Journal of Emergency Medicine; S0736-4679(20)30398-X.

Dong L., J. Tian, S. He, C. Zhu, J. Wang, C. Liu, et al., 2020. Possible vertical transmission of SARS-CoV-2 from an infected mother to her newborn JAMA (2020), 10.1001/jama.2020.4621.

Du M, Cai G, Chen F, Christiani DC, Zhang Z. and Wang M. 2020. Multi-omics Evaluation of Gastrointestinal and Other Clinical Characteristics of SARS-CoV2 and COVID-19. Gastroenterology.

Favre G, Pomar L, Musso D and Baud D. 2020. 2019-nCoV epidemic: what about pregnancies? Lancet. 395(10224): e40.

Gao, Q.Y., Chen, Y.X. and Fang, J.Y. 2020. 2019 novel coronavirus infection and gastrointestinal tract. J. Dig. Dis. 17512980.12851.

Graaf de M, Beck R and ltand Caccio SM. 2017. Sustained Oral fecal-to-HumanHuman Transmission following Event A zoonotic. Curr Opin Virol. 22:1-. 6.

Gu J, Han B and Wang J. (2020) COVID-19: Gastrointestinal Manifestations and Potential Fecal-Oral Transmission.
Gastroenterology; 158: 1518-1519.

Guo YR, Cao QD, Hong ZS, Tan YY, Chen SD, Jin HJ, Tan KS, Wang DY and Yan Y. (2020) The origin, transmission and clinical therapies on coronavirus disease 2019 (COVID-19) outbreak - an update on the status. Mil Med Res. Mar 13; 7(1): 11 .

Hamming I, Timens W, Bulthuis ML. (2004) Tissue Distribution of ACE2 Protein, The Functional receptor for of SARS coronavirus A First STEP in Understanding of SARS pathogenesis. J Pathol. 203(2): 631-637.

Hart OE and Halden RU. (2020) Computational analysis of SARS-CoV2/COVID-19 surveillance by wastewater-based epidemiology locally and globally: Feasibility, economy, opportunities and challenges. Science of the Total Environment 730:138875.

Hellmer M, Paxéus, N., Magnius, L., Enache, L., Arnholm, B., Johansson, A., Bergström, T. and Norder, H. (2014) Detection of pathogenic viruses in sewage provided early warnings of hepatitis A virus and norovirus outbreaks. Appl. Environ. Microbiol. 80:6771-6781.

Holshue ML, DeBolt C. and Lindquist S. (2020) First case of 2019 novel coronavirus in the United States. N Engl J Med. 382: 929-936.

Hospodsky D. (2015) Characterizing airborne fungal and bacterial concentrations and emission rates in six occupied children's classrooms. Indoor Air. 25: 641-52.

$\mathrm{Hu}$ K, Patel J. and Patel BC. (2020) Ophthalmic Manifestations of Coronavirus (COVID-19). 2020 Apr 22. In: Stat Pearls [Internet]. Treasure Island (FL): Stat Pearls Publishing.

Hussain S, Pan J, Chen Y, Yang Y, Xu J. and Peng Y. (2005) Identification of novel subgenomic RNAs and noncanonical transcription initiation signals of severe 
acute respiratory syndrome coronavirus. J Virol. 79(9):5288-95.

Jianyun L, et al., COVID-19 outbreak associated with air conditioning in restaurant, Guangzhou, China, 2020. Emerging Infectious Disease journal. 26:2020.

Johnson GR (2011) Modality of human expired aerosol size distributions. J Aerosol Sci. 42:839-51.

Karimi S, Arabi A, Shahraki T. and Safi S. (2020) Detection of severe acute respiratory syndrome Coronavirus- 2 in the tears of patients with Coronavirus disease 2019. Eye. 18:1-4.

Kimberlin, D.W., StagnoS. 2020. Can SARS$\mathrm{CoV}-2$ infection be acquired in utero? More definitive evidence is needed. JAMA. 10.1001/jama.2020.4868.

Kissler, S.M., Tedijanto, C., Goldstein, E., Grad, Y.H., Lipsitch, M. 2020. Projecting the transmission dynamics of SARS-CoV-2 through the postpandemic period.

Science.eabb5793.https://science.scienc emag.org/content/sci/early/2020/04/14/s cience.abb5793.

Kwan, S. E., Shaughnessy, R., HaverinenShaughnessy, U., Kwan, T. A. \&Peccia, J. 2020. The impact of ventilation rate on the fungal and bacterial ecology of home indoor air. Building and Environment, 106800.177:106800.

La Rosa, G., Iaconelli, M., Mancini, P., Bonanno Ferraro, G., Veneri, C. and Bonadonna, L. 2020. First Detection of SARS-CoV-2 in Untreated Wastewaters in Italy. Science of The Total Environment. 736: 139652.

Li W, Moore MJ, Vasilieva N, Sui J, Wong SK, Berne MA, Somasundaran M, Sullivan JL, Luzuriaga K, Greenough TC, Choe H and Farzan M. 2003. Angiotensin-converting enzyme 2 is a functional receptor for the SARS coronavirus. Nature. 426(6965):450
454.

Liang H and Acharya G. 2020. Novel corona virus disease (COVID-19) in pregnancy: what clinical recommendations to follow? Acta Obstet Gynecol Scand. 99(4): 439-442.

Liu D, Li L, Wu X, Zheng D, Wang J, Yang L and Zheng C. 2020a. Pregnancy and Perinatal Outcomes of Women with Coronavirus Disease (COVID-19) Pneumonia: A Preliminary Analysis. AJR Am J Roentgenol. Pp. 1-6.

Liu F, Xu A, Zhang Y, Xuan W, Yan T, Pan K, Yu W and Zhang J. 2020b. Patients of COVID-19 may benefit from sustained Lopinavir-combined regimen and the increase of Eosinophil may predict the outcome of COVID-19 progression. Int $\mathrm{J}$ Infect Dis. 95:183191.

Liu H, Wang LL, Zhao SJ, Joanne KK, Mor $G$ and Liao AH. 2020c. Why are pregnant women susceptible to COVID19? An immunological viewpoint: Review. Journal of Reproductive Immunology. 139:103122.

Liu Z, Xiao X and Wei X. 2020b. Composition and divergence of coronavirus spike proteins and host ACE2 receptors predict potential intermediate hosts of SARS-CoV-2. J Med Virol. 92(6): 595-601.

Lodder W. andDe RodaHusman A. 2020. SARS-CoV-2 in wastewater: potential health risk, but also data source. Lancet Gastroenterol. Hepatol. 1253, 30087.

Loon S, Teoh S, Oon L, Se-Thoe S, Ling A, Leo Y. and Leong H.2004. The severe acute respiratory syndrome coronavirus in tears. $\mathrm{Br} \mathrm{J}$ Ophthalmol.88(7):861863.

Lu CW, Liu XF. and Jia ZF. 2020. 2019nCoV transmission through the ocular surface must not be ignored. Lancet. 22:395(10224):e39.

Mardani M and Pourkaveh B. A. 2020. 
Controversial Debate: Vertical Transmission of COVID-19 in Pregnancy. Neoscriber Demo Publisher. Archives of Clinical Infectious Diseases. 15 (1): e102286.

Medema G, Heijnen L, Elsinga G. and Italiaander R. 2020. Presence of SARSCoronavirus-2 in Sewage. Environmental Science \& Technology Letters doi: 10.1021/acs.estlett.0c00357. National Health Commission of the People's Republic of China. 2020. Epidemic prevention and control dynamics (Chinese). http://www.nhc.gov.cn/.

Nemudryi, A., Nemudraia, A., Surya, K., Wiegand, T., Buyukyoruk, M., Wilkinson, R.2020. Temporal detection and phylogenetic assessment of SARS$\mathrm{CoV}-2$ in municipal wastewater.

New Group of Experts on the prevention and control of Chinese Preventive Medicine Association coronavirus pneumonia. 2020. The latest understanding of the epidemiological characteristics of pneumonia novel coronavirus [J / OL]. Chinese Journal of Epidemiology. Chinese Journal of Epidemiology. 41(12).

Perrier A, Bonnin A, Desmarets L, Danneels A, Goffard A. and Rouille Y.2019. The C-terminal domain of the MERS coronavirus $\mathrm{M}$ protein contains a transGolgi network localization signal. J Biol Chem. 294(39): 14406-21.

Po Ying Chia, Kristen Kelli Coleman, Yian Kim Tan, Wei Xiang Ong, Marcus Gum, et al., 2020. Detection of air and surface contamination by severe acute respiratory syndrome coronavirus 2 (SARS-CoV-2) in hospital rooms of infected patients. Nature Communications, doi: 10.1038/s41467020-16670-2.

Qia J. 2020. What are the risks of COVID-19 infection in pregnant women? Lancet. 395(10226):760-762.
Randazzo, W., Cuevas-Ferrando, E., Sanjuan, R., Domingo-Calap, P. and Sanchez, G. 2020a. Metropolitan Wastewater Analysis for COVID-19 Epidemiological Surveillance. (Los Angeles, CA, 2020). International journal of hygiene and environmental health. Doi: 10.1016/j.ijheh.2020.113621

Rasmussen SA, Smulian JC, Lednicky JA, Wen TS and Jamieson DJ. 2020. Coronavirus Disease 2019 (COVID-19) and pregnancy: what obstetricians need to know. Am J Obstet Gynecol. S00029378(20)30197-6.

Read, R., 2020. A choir decided to go ahead with rehearsal. Now dozens of members have COVID-19 and two are dead.(Accessed at www.latimes.com/worldnation/story/2020-03-29/coronaviruschoir-outbreak).

Santarpia, J. L.(2020) Transmission potential of SARS-CoV-2 in viral shedding observed at the University of Nebraska Medical Center. Med Rxiv. 2003.2023.20039446.

Sawicki SG and Sawicki DL. 2005. Coronavirus transcription: a perspective. Curr Top Microbiol Immunol. 287: 31-55.

Schwartz DA and Graham AL. 2020. Potential Maternal and Infant Outcomes from (Wuhan) Coronavirus 2019-nCoV Infecting Pregnant Women: Lessons from SARS, MERS, and Other Human Coronavirus Infections. Viruses. 12(2): 194.

Schwartz DA. 2020a. An Analysis of 38 Pregnant Women with COVID-19, Their Newborn Infants, and MaternalFetal Transmission of SARS-CoV-2: Maternal Coronavirus Infections and Pregnancy Outcomes. Arch Pathol Lab Med. Doi: 10.5858/arpa.2020-0901-SA.

Seah I and Agrawal R. 2020. Can the 
Coronavirus Disease 2019 (COVID-19)

Affect the Eyes? A Review of Coronaviruses and Ocular Implications in Humans and Animals. Ocul. Immunol. Inflamm. 28(3):391-395.

Sinclair RG, Choi CY, Riley MR and Gerba CP. 2008. Pathogen surveillance through monitoring of sewer systems. Adv. Appl. Microbiol. 65, 249-269.

Tasnim Agency. 2020. Birth of a neonate from infected mother COVID-19 in Babol city: https://www.tasnimnews.com/fa/news/1 398/12/14/2216407/.

Tian Y, Rong L, Nian W and He Y. 2020. Review article: gastrointestinal features in COVID-19 and the possibility of faecal transmission. Aliment Pharmacol Ther; 51: 843-851.

Tortorici MA and Veesler D. 2019. Structural insights into coronavirus entry. Adv Virus Res.105:93-116.

Walls AC, Park YJ, Tortorici MA, Wall A, McGuire AT and Veesler D.2020. Structure, function and antigenicity of the SARS-CoV-2 spike glycoprotein. Cell 2020.

Wan Y, Shang J, Graham R, Baric RS and Li F. 2020. Receptor recognition by novel coronavirus from Wuhan: an analysis based on decade-long structural studies of SARS. Virol.Doi:10.1128/JVI.00127-20.

Wang L, Shi Y, Xiao T, Fu J, Feng X, Mu D, Feng Q, et al., 2020a. Working Committee on Perinatal and Neonatal Management for the Prevention and Control of the 2019 Novel Coronavirus Infection. Chinese expert consensus on the perinatal and neonatal management for the prevention and control of the 2019 novel coronavirus infection (First edition). Ann Transl Med. 8(3):47.

WangN., X. Shi, L. Jiang, S. Zhang, D. Wang, TongP. 2013. Structure of MERS-CoV spike receptor-binding domain complexed with human receptor DPP4Cell Res, 23 (8), p. 986.

Weiss SR, Navas-Martin S. 2005. Coronavirus pathogenesis and the emerging pathogen severe acute respiratory syndrome coronavirus. Microbiol Mol Biol Rev.69(4):635-664.

World Health Organization, 2020. 2019nCoV situation reports. 2020. https://www.who.int/emergencies/diseas es/novel-coronavirus-2019/situationreports, Accessed date:10 February 2020.

Wrapp D, Wang N and Corbett KS. 2020. Cryo-EM structure of the 2019-nCoV spike in the prefusion conformation. Science. 367:1260-3.

Wu F, Xiao A, Zhang J, Gu X, Lee W, Kauffman K, et al., 2020b. SARS-CoV2 titers in wastewater are higher than expected from clinically confirmed. American Society for Microbiology Journals.

DOI https://doi.org/10.1128/mSystems.0061 4-20.

Wu P, Duan F and Luo C. 2020a. Characteristics of ocular findings of patients with coronavirus disease 2019 (COVID-19) in Hubei Province, China. JAMA Ophthalmol. 138(5): 575-578.

Wurtzer, S., Marechal, V., Mouchel, J.-M. and Moulin, L. 2020. Time course quantitative detection of SARS-CoV-2 in Parisian wastewaters correlates with COVID-19 confirmed cases. Med Rxiv preprint.

Doi: https://doi.org/10.1101/2020.04.12.2006 2679.

Xagoraraki I, O'Brien E. 2020. Wastewaterbased epidemiology for early detection of viral outbreaks. In: O'Bannon, D. (Ed.), Women in Water Quality. Springer Nature Switzerland, pp. 75-97. https://doi.org/10.1007/978-3-03017819-2.

Xiao F, Tang M, Zheng X, Liu Y, Li X and 
Shan H. 2020. Evidence for Gastrointestinal Infection of SARSCoV-2. Gastroenterology. 158: 18311833.

Yang Z, Li G, Dai X, Liu G, Li G andJie Y. 2020. Three cases of novel coronavirus pneumonia with viral nucleic acids still positive in stool after throat swab detection turned negative. Chin J Dig.40: E002-E002.

Yu P, Zhu J, Zhang Z and Han Y. 2020. A familial cluster of infection associated with the 2019 novel coronavirus indicating possible person-to-person transmission during the incubation period. J Infect Dis.221(11):1757-1761.

Zeng H., C. Xu, J. Fan, Y. Tang, Q. Deng, W. Zhang et al.2020. Antibodies in infants born to mothers with COVID-19 pneumonia.

JAMA. 10.1001/jama.2020.4861.

Zhang H, Kang Z, Gong H, Xu D, Wang J, Li Z, Cui X, Xiao J, Meng T, Zhou W, Liu $\mathrm{J}$ and $\mathrm{Xu} \mathrm{H}$. 2020a. The digestive system is a potential route of 2019nCov infection: a bioinformatics analysis based on single-cell transcriptomes.BioRxiv.Doihttps://doi.o rg/10.1101/2020.01.30.927806.
Zhang J, Wang S and Xue Y. 2020b. Fecal specimen diagnosis 2019 novel coronavirus-infected pneumonia. J Med Virol.https://doi.org/10.1002/jmv.25742

Zhang Z, Wang C and Gao CC. 2020c. Neonatal coronavirus expert confirmed at 30 hours of birth: vertical transmission from mother to infant. http://www.cnr.cn/hubei/yuanch uang/20200205/t20200205_524961963. shtml.

ZhongN., B. Zheng, Y. Li, L. Poon, Z. Xie and ChanK. 2003. Epidemiology and cause of severe acute respiratory syndrome (SARS) in Guangdong, People's Republic of China. The Lancet, 362 (9393) pp. 1353-1358.

Zhou P, Yang XL, Wang XG, Hu B, Zhang L and Zhang W. 2020. A pneumonia outbreak associated with a new coronavirus of probable bat origin. Nature.

Zhu H, Wang L, Fang C, Peng S, Zhang L, Chang G, Xia S and Zhou W. 2020a. Clinical analysis of 10 neonates born to mothers with 2019-nCoV pneumonia. Transl Pediatr.9(1):51-60.

\section{How to cite this article:}

Rupali Masand, Abhilash Jadhao and Sameer Jadhav. 2021. A Review on Modes of Transmission of COVID-19. Int.J.Curr.Microbiol.App.Sci. 10(02): 1003-1014. doi: https://doi.org/10.20546/ijcmas.2021.1002.118 